Paper ID \#18313

\title{
Manual Revision Process for Project-Based Laboratory Instruction
}

\section{Prof. Gene Hou, Old Dominion University}

Dr. Gene Hou is a Professor in the Department of Mechanical and Aerospace Engineering of Old Dominion University (ODU). He received his PhD in Mechanical Engineering from University of Iowa in 1983 and joined Old Dominion University since then. His expertise is in computational mechanics, multidisciplinary design optimization and system integration and risk management. He is the co-director of the Marine Dynamics Laboratory. During his tenure, he has the privilege of developing 3 new undergraduate and 6 new graduate courses in the areas related to computational methods and design.

\section{Prof. Feifei Zhong, Southwest Jiaotong University}

Mrs. Feifei Zhong is a lecturer teaching non-English majors English in the School of Foreign Languages, Southwest Jiaotong University, Chengdu, China. She received her Master's degree in Applied Linguistics from Southwest Jiaotong University in 2007 and joined Southwest Jiaotong University since then. Her research interest is in effective English learning strategies. She was the first place winner of universitywise Teaching Competition in 2007 and 2013.

\section{Dr. Orlando M. Ayala, Old Dominion University}

Dr. Ayala received his BS in Mechanical Engineering with honors (Cum Laude) from Universidad de Oriente (Venezuela) in 1995, MS in Mechanical Engineering in 2001 and PhD in Mechanical Engineering in 2005, both from University of Delaware (USA). Dr. Ayala is currently serving as Assistant Professor of Mechanical Engineering Technology Department, Frank Batten College of Engineering and Technology, Old Dominion University, Norfolk, VA.

Prior to joining ODU in 2013, Dr. Ayala spent three years as a Postdoctoral Researcher at University of Delaware where he expanded his knowledge on simulation of multiphase flows while acquiring skills in high performance parallel computing and scientific computation. Before that, Dr. Ayala hold a faculty position at Universidad de Oriente at Mechanical Engineering Department where he taught and developed graduate and undergraduate courses for a number of subjects such as Fluid Mechanics, Heat Transfer, Thermodynamics, Multiphase Flows, Fluid Mechanics and Hydraulic Machinery, as well as Mechanical Engineering Laboratory courses.

In addition, Dr. Ayala has had the opportunity to work for a number of engineering consulting companies, which have given him an important perspective and exposure to industry. He has been directly involved in at least 20 different engineering projects related to a wide range of industries from petroleum and natural gas industry to brewing and newspaper industries. Dr. Ayala has provided service to professional organizations such as ASME. Since 2008 he has been a member of the Committee of Spanish Translation of ASME Codes and the ASME Subcommittee on Piping and Pipelines in Spanish. Under both memberships the following Codes have been translated: ASME B31.3, ASME B31.8S, ASME B31Q and ASME BPV Sections I.

While maintaining his industrial work active, his research activities have also been very active; Dr. Ayala has published 90 journal and peer-reviewed conference papers. His work has been presented in several international forums in Austria, USA, Venezuela, Japan, France, Mexico, and Argentina. Dr. Ayala has an average citation per year of all his published work of 33.25 . 


\title{
Manual Revision Process for Project-Based Laboratory Instruction
}

\begin{abstract}
A four-step laboratory manual revision process was developed in this study based upon a technical writing process for supporting project-based laboratory classes. The audience and the objectives of this type of laboratory manuals are quite different from those of traditional, descriptive laboratory classes. The project-based laboratory manual has to serve as both an operational handbook and a theoretical textbook. The proposed four-step manual revision process was implemented in the fall 2016 semester in a 3-credit, senior elective class which was built upon a commercially-rated finite element analysis software package. Student surveys and evaluations showed that the revision process greatly increased student engagement in the class and, as a result, increased student learning effectiveness.
\end{abstract}

\section{Introduction}

Laboratories have long been recognized as excellent tools for allowing students to observe, discover and test new concepts. It is thus important for engineering schools to integrate instructional laboratories as part of their undergraduate curriculums. However, good laboratory instruction must meet a broad range of objectives that include the capability to conduct experiments, to learn new subject matters, and to solve real world problems ${ }^{1,2}$. Designing and delivering effective laboratory instruction remains a challenging endeavor for many engineering faculty. Since most laboratory instructions are supported by laboratory manuals, this paper will investigate the importance of laboratory manuals on laboratory instruction effectiveness and propose a process for its continuous revision with the goal of achieving more effective laboratory experience for students overall.

Most hands-on laboratories offered in standard engineering curriculums are designed to enhance the basic knowledge that students have previously acquired from fundamental courses that they have taken in their sophomore or early junior years. Laboratory manuals for these courses, for most part, serve as instruction manuals detailing the procedures necessary to conduct the experiments. They are often referred to as descriptive laboratory manuals. Students are mainly instructed to follow the procedures to acquire data, present any collected data in the forms of tables or graphs, and correlate the results to the particular theories, hypotheses, or models that they learned in prior classes. Students usually do not put much effort into these laboratory classes, which are usually assigned with only one credit hour and taught by graduate students. Efforts have been made recently to improve learning effectiveness. Some studies have looked into improving laboratory instruction from the perspectives of teaching assistants and students ${ }^{3}$. Other studies have proposed alternative teaching methodologies, such as the framework of Legacy Cycle ${ }^{4,5,6}$, a web-based four step tutorial, LabWrite ${ }^{7}$, multimedia course content $^{8,9}$ and pre-laboratory e-learning lessons ${ }^{10}$.

New types of laboratory courses have recently been developed and introduced in many upper level engineering curriculums. They have emerged in response to demand for specialized 
training in ever growing and changing technologies, such as cybersecurity, alternative energy, drone technology, etc. These types of laboratory classes are project-based and inquiry-oriented. Students in these classes are required to acquire and learn new concepts and new knowledge. They have to be able to alter the experimental procedures for the sake of exploration and exploitation. Thus, the audience, the objective, and the content of the laboratory manuals that support these new types of laboratory classes are quite different from those of the traditional, descriptive ones. Furthermore, as new technologies continue to progress rapidly and course content and laboratory instrumentation continue to evolve in order to keep pace, laboratory manuals will also have to be revised frequently in order to stay relevant and effective.

A laboratory manual revision process was developed in this study in order to support these new types of laboratory classes. It is a four-step process, which includes: 1) Collecting Audience Responses, 2) Scaffolding the Class Project, 3) Project Report Writing Requirement and 4) Peer-Review and Reflection. This development was carried out based upon the technical writing framework, as it is believed that technical writing can promote critical thinking and active learning, not only for students who take the laboratory class, but also for instructors who prepare the laboratory manual ${ }^{11,12}$. The technical writing process has been widely used to guide students in writing laboratory reports. In this study, the same process, is used to guide instructors in revising laboratory manuals. A three-hour senior elective class, MAE 441 Computer-Aided Engineering, was used in this study to investigate the effectiveness of the developed revision process. The instrument of the class was the commercially-rated finite element analysis software, NASTRAN and PATRAN. The main learning outcome for the class was the ability of students to identify and formulate an engineering problem and design a solution process using modern engineering tools. The class was equally divided into lectures and laboratory sessions. No textbook was used in this class. The only reference book used was the laboratory manual. The implementation details of the proposed laboratory manual revision process to MAE 441 are discussed hereafter, along with class evaluations and feedback collected from students.

The rest of the paper is organized as follows. Section II outlines the technical writing process and its uses as a framework for examining existing literature about laboratory instruction and manual preparation. Section III presents the objectives and the content of MAE 441, which was selected as a demonstrative sample class. Section IV discusses the revisions made to the MAE 441 laboratory manual, based upon the proposed revision process. Section V describes the assessment of the proposed laboratory manual revision process that was conducted after completion of the course. Section VI summarizes the findings to conclude the study.

\section{Technical Writing Process and Laboratory Instruction}

Technical writing re-enforces learning and critical thinking as it involves research, organization, and reasoning. Students are often encouraged to follow the technical writing procedure to write their laboratory reports. However, in this study, it was the instructors who were encouraged to revise their laboratory instruction manuals following the technical writing process. 
The importance of technical writing in education has been long recognized by almost every university campus. Under the Quality Enhancement Plan, Old Dominion University (ODU) has been regularly offering Improving Disciplinary Writing (IDW) workshops for its faculty since 2014. The IDW workshop divides the technical writing process into six steps: prewriting planning, research, drafting, reviewing, revising, and editing. It also emphasizes four important features of effective writing: role, audience, format, and task (RAFT). This six-step technical writing process, along with RAFT, serves as the base for laboratory manual revision.

Laboratory manual writing is very different from textbook writing, just as laboratory instruction is very different from regular lecture classes. The former has to deal with various hardware and software tools that are used to conduct the experiment, as well as technical theories that must be employed to interpret the outcome of the experiment. Effective laboratory instruction also demands more student-instructor interaction than a regular lecture class. Therefore, the goal of laboratory manual writing should facilitate laboratory instruction that is both effective for helping students learn and effective for helping instructors teach. The term instructors referred here, includes both teaching assistants and faculty. To achieve both learning and teaching effectiveness, laboratory manuals should be written for a target audience that includes students as well as instructors, as both will be the users of the manual. As far as formatting is concerned, laboratory manuals cannot be simple cookbooks and they should not be theoretical textbooks, neither. At times laboratory manuals must deal effectively with both hardto-implement instrumentation procedures as well as hard-to-explain theoretical concepts. Finally, laboratory content design must also be considered to maximize student engagement in the laboratory project. Scaffolding the laboratory projects in a way that gradually builds up the complexity of the assignment from low-stake tasks to more challenging higher level undertakings is important so that students do not become frustrated, and consequently disengaged, in the early stages of the laboratory class. This is specifically true for complicated class projects.

A ten-step writing process was introduced and employed by Dupen in writing a textbook for a lecture-style class on Strength of Materials ${ }^{13}$. It can be meshed well into the six stepprocess introduced in ODU's IDW workshop. The audience of the textbook was his students at his own institution. Dupen used existing textbooks as a baseline for improvement and collected feedback from his past students to determine the topics that required extra attention. For such topics, he provided scaffolding exercises, some of which were presented in a step-by-step cookbook format. Interestingly, the author collected feedback from current students in order to guide future improvements in his textbook. He assigned homework at the end of each chapter, requiring his students to submit recommendations for edits that were both specific and actionable. This type of reviewing assignment is particularly important for making meaningful revisions to laboratory manuals used in project-based laboratory courses.

Efforts have been made recently to design various models to guide laboratory instruction in a more structured manner. Balta developed a five-step model for Science Laboratory Instructional Design (SLID), which consists of establishing a goal, safety precautions, proper laboratory execution, a laboratory report, and a rapid feedback system ${ }^{14}$. The surveyed results of 
thirty-four high school science teachers in Turkey confirmed that the SLID is essential for laboratory instruction.

Efforts have also been made to divide laboratory learning into distinct modules based upon the framework of the Legacy Cycle ${ }^{4,5,6}$. The Legacy Cycle is made of seven steps: 1) look ahead and reflect back, 2) the challenge, 3) generate ideas, 4) multiple perspectives, 5) research and revise, 6) test your mettle, and 7) go public. Steps 1) to 5) are related to pre-lab learning, which requires the support of a web-based, resource rich, technology-enhanced environment. Go public is the last step in the Legacy Cycle which requires participating students to submit their laboratory reports. One special feature of the Legacy Cycle is that it can be repeated in sequential years. The feedback or lessons learned from prior classes, are documented in the "reflection" task at the conclusion of a given laboratory module. At the start of a new laboratory module, those lessons will then be reviewed and discussed in the initial "reflect back" step that is included with "look ahead." In this way, "reflect back" enables the instructors to preserve the legacy data from previous classes and to share the past laboratory learning experiences with new students.

Watai et al. implemented the Legacy Cycle into nine circuit laboratory units, which were all part of a regular four credit hour Network Theory I class ${ }^{6}$. The class and individual laboratory units were usually taught and supervised by teaching assistants. The results of the Legacy Cycle implementation were very encouraging, based on the feedback of students as well as teaching assistants who were involved. The same format was later extended to Electronics Lab (EECE 235). Following the guidelines of the Legacy Cycle, Pandy et al. developed a multimedia-based learning module as a part of senior-level undergraduate biomechanics course 15. Though the data was limited, the study showed that the Legacy Cycle approach, combined with enhanced multimedia resources and computer simulation capabilities, did accelerate the student learning process. The Legacy Cycle has also been shown to be effective for teaching technical writing in a laboratory environment. By implementing the steps of the Legacy Cycle in a tissue engineering laboratory module, Yalvac, et al. were able to show that students became more proficient in technical writing ${ }^{4}$. Furthermore, despite concerns that the structured steps of the Legacy Cycle would be detrimental to student engagement, there was no detraction from overall gains in student comprehension of the core engineering knowledge of the laboratory class .

LabWrite is an web-based tutorial that is designed to help students conduct and reflect on their laboratory experience, and write their laboratory report ${ }^{5}$. LabWrite is structured in four steps: PreLab, InLab, PostLab and LabCheck. PreLab asks students to identify and write down the objectives and related concepts or hypotheses that will be explored in the laboratory session to be conducted. InLab details instructions about the experimental setup, data collection, and analysis. It also allows students to make notes about the laboratory experience. PostLab provides students a step-by-step guide to build their laboratory reports, section by section. LabCheck gives students the opportunity to review and self-evaluate their laboratory report so as to identify possible areas for improvement. 
In order to identify the specific deficiency in a laboratory manual, Girault, et al. used the Hierarchical Task Diagram ( HTD ) to model the entire process of executing an experiment ${ }^{16}$. At the top level of the HTD is the "activity", which defines the specific scientific problem to be solved and the rationale for the experiment overall. At the bottom level of the HTD are the individual "operations", which define specific parameters or tasks which are performed throughout the experiment to achieve larger goals and ultimately complete the experiment. Thirty-nine laboratory manuals were evaluated by four teachers and four researchers based upon the evaluation criteria developed by a collaborative effort of six teachers using the HTD model. The results of their evaluations showed that, often, laboratory manuals do not present laboratory procedures very clearly. Many of the evaluated laboratory manuals were noted to having procedures that were missing important specific tasks. The missing tasks were often found to be the structured tasks and the action tasks. These "structured" tasks, which are related to the strategic plan of the work flow, are in the lower levels of the HTD, between the overall "activity" at the top and the specific "operations" at the bottom. .

Though the research studies reviewed above were mostly related to laboratory instruction, they do show that laboratory manual revision has to be an organic, on-going process, guided by user feedback, instructional scaffolding, and the availability of technology resources. Furthermore, the studies reviewed here also revealed an important observation. That is that effective laboratory instruction should involve more than just the faculty in charge of developing the laboratory class. Both teaching assistants and students who take the laboratory class should also be involved. In other words, the target audience for any laboratory manual should include not only the students but also the faculty and teaching assistants as well.

\section{MAE 441 Computer-Aided Design of Mechanical Systems}

A project-based class, MAE 441 Computer-Aided Design of Mechanical Systems, was selected for implementation and testing of the proposed laboratory manual revision process. The class was a three-credit senior level elective course. This section will briefly describe the objectives, the content and the format of the class. The objectives of the class were set to satisfy the following ABET requirements:

1) An ability to apply knowledge of mathematics, science, and engineering.

2) An ability to identify, formulate, and solve engineering problems.

3) An ability to communicate effectively.

4) An ability to use the techniques, skills, and modern engineering tools necessary for engineering practices.

The class met twice a week. One was for common lectures and the other was for laboratory sessions. Each class lasted 75 minutes long. In the first part of the semester, the classes were designed to teach the syntax of commercially rated software, NASTRAN and PATRAN, enabling students to build finite element models and interpret the associated output. NASTRAN is the core of finite element analysis, while PATRAN is the GUI, supporting NASTRAN with graphical input and output display. In the second part of the semester, the entire class was devoted to a class project which required students to test and analyze a real world structure. No textbook was used in the class. The printed laboratory manual was the only handout for the class. The laboratory manual was used as a test subject to facilitate the investigation of the effectiveness of the proposed revision process. 
Initially, the laboratory manual was 216 pages in length, covering six chapters in total. Chapter I introduced the login process and file management. Chapter 2 and Chapter 3 occupied the majority of the manual. NASTRAN was presented in Chapter 2 over the course of 61 pages and PATRAN was presented in Chapter 3 over the course of 83 pages. Most of Chapters 2 and 3 were discussed in the classroom prior to starting the class project. The rest of the chapters in the manual covered special applications of PATRAN in vibration, transient analysis, and composite panels.

The ASCE steel bridge shown in Figure 1 was selected as the class project for both 2015 and 2016 fall semesters. The dimensions of the bridge were as follows: 18 feet long, 3 feet wide, and 2 feet high. The bridge was made of various sizes of beams which were connected by 42 bolt joints through interface plates. Students in the class were divided into teams of two. Each team was required to conduct an experimental investigation and develop simple analytical models to estimate the responses of the bridge under different loads. Students were expected to perform a complete structural analysis using three different techniques: experimental investigation, analytical calculations, and finite element analysis; each of which constituted a task. The experimental data was collected through the strain and dial gauges mounted on the loaded bridge. As shown in Figure 2, students sitting on the bridge served as the loads. The experimental data was used as a baseline to justify the results of the other two approaches. Next, analytical calculations were performed for a simplified model of the bridge to provide an estimate of the solutions. The results from these calculations came in the form of deflections and stresses. Finally, the finite element model, constructed in PATRAN and NASTRAN, provided a visual representation of the bridge along with stress and deflection data gathered without major geometric simplification. The results of structural analyses using three different techniques provide an opportunity for students to investigate the validity of each of these techniques and to gain insight into the fundamental concepts of structural mechanics.

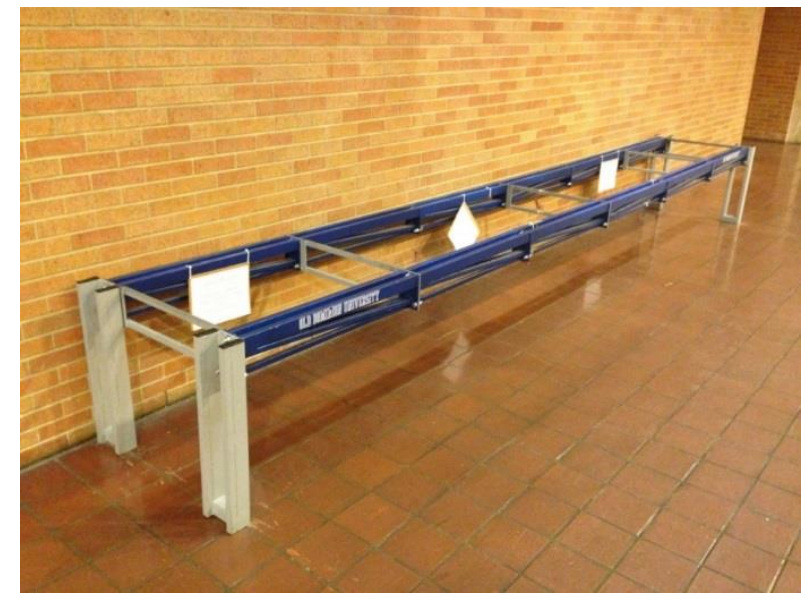

Figure 1. Model Steel Bridge 


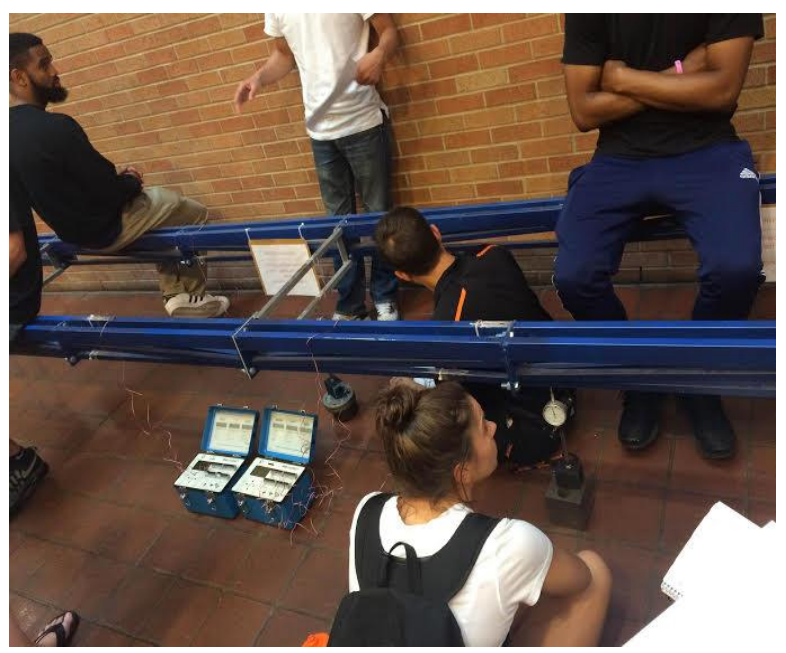

Figure 2. Data Collection during the Experimental Task

Before implementing the laboratory manual revision process proposed in this paper, MAE441 was already taught in the fall 2015 semester using the same steel bridge as the class project. Sixty-seven students, grouped into 33 teams, were registered at that time. Most of the teams struggled to create a proper PATRAN/NASTRAN model of the bridge. Students avoided the use of simple 1D beam elements in the model and instead used 2D type elements. Many also failed to include the bolted joints in their modeling of the bridge. Even with help of three teaching assistants, 9 out of the 33 teams were unable to get their models to work properly. All that represented a major deficiency in the laboratory instruction. Furthermore, the lead teaching assistant was not going to be available for the fall 2016 semester to help out with the class. As such, it became urgent to revise the laboratory manual in order to improve the learning outcomes for the laboratory class and, at the same time, reduce the negative impact of losing an experienced teaching assistant on laboratory instruction.

\section{Laboratory Manual Revision}

Given the poor outcomes, in terms of student proficiency, at the conclusion of the MAE 441 class the previous year, the authors along with the remaining teaching assistants decided to improve the laboratory instruction by revising the laboratory manual. The revision process started in the summer of 2016 before the class started in fall. The major steps in the process were collecting audience responses, scaffolding the class project, project report writing assignment, and peer-review and reflection. Detailed discussion of each of these steps and its implementation are listed below.

\section{Collecting Audience Responses}

Several selected students who took the class in the fall 2015 semester were interviewed about their specific learning difficulties and asked to suggest actionable recommendations for improvement to the laboratory manual. The instructors, including the faculty and the teaching assistants, then worked as a group to develop a revision plan based upon feedback from the interviewed students. These audience survey and response meetings were continuously 
conducted throughout the entire fall 2016 semester. Some revisions, such as typo and grammar errors, were resolved immediately. Others had to be implemented later in the semester or after the semester was over.

In the initial survey, the majority of surveyed students reported having difficulty during the laboratory understanding how to handle the orientation vector of a beam element and how to model a bolted joint using a rigid element. As a result, shortly after the interviews, an interactive learning module was created using the Adobe flash player to demonstrate the use of an orientation vector through various examples. This was introduced to the class as part of the laboratory manual. Additionally, a bolted plate example was also worked out in detail using PATRAN and included in the revised laboratory manual. The bolted plate example was carefully selected from the textbook of the MAE332 Machine Design class (which is a pre-requisite class of MAE 441) in order to ensure that all students in the class would be familiar with the example.

\section{Scaffolding the Class Project}

The steel bridge used in the class project (Fig. 1), is a built-up structure made of multiple layers of beams and plates that are bolted together. Therefore, in order for students to work on this project effectively, they need to be able to model not only beams and plates separately but also be able to model them together using bolted joints. Though the original laboratory manual had step-by-step examples of individual plates, beams, and bolted joints in their respective sections, the manual did not provide any examples of built-up structures made of plates and beams that were bolted together. As a result, students were often unsure how to integrate the separate components in their models. Consequently, the instructors decided to develop and implement a new laboratory exercise as part of the laboratory manual. This exercise used a much simpler bridge assignment to mimic the steps required to model more complex structures like the one in the class project.

The assembly of the sample bridge exercise problem is shown in Fig. 3. The sample bridge was designed with three beams attached to two end plates. The beams were designed to be welded to the inner plate which was then bolted to the outside plate with three bolts. The stepby-step procedure for modeling this simplified bridge was provided in the revised laboratory manual, including steps for building the PATRAN model as well as plotting the final NASTRAN results. The PATRAN model of the simple bridge is shown in Fig. 4, where the red links represents the rigid elements that model the bolted joints as well as the welded joints. This exercise aimed to serve as a stepping stone for students to move on with confidence to the more complicated steel bridge project. In addition to this exercise, two topics were added to the class lecture; one reviewing the theory of simple supported beams and the other on the error analysis of finite element methods. Both topics were designed to help students to understand the limits of the finite element methods. 


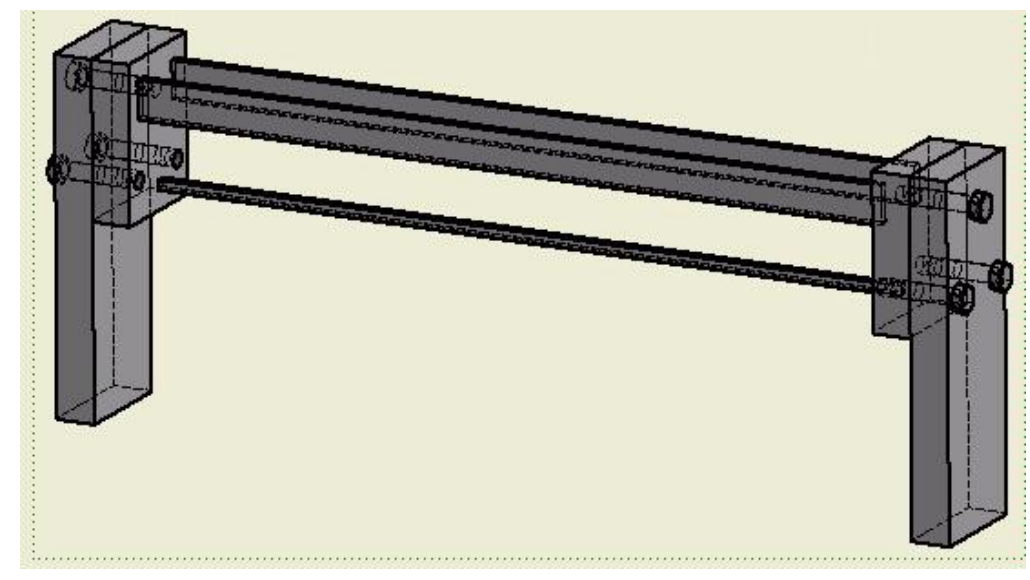

Figure 3. Simple Steel Bridge

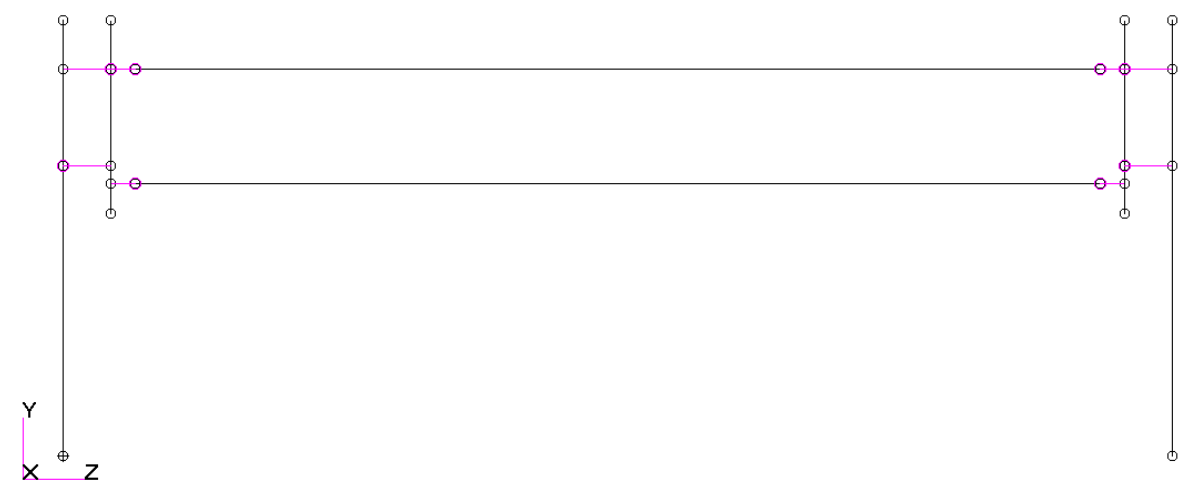

Figure 4. PATRAN models of Beams, Plates and Bolt Joints

\section{Project Report Writing Assignment}

Project report writing has been a component of this class for a while in order to meet the ABET requirement of teaching effective technical communication. However, since students often struggled with the class project and were unable to produce the necessary results, they were often reluctant to spend significant time on report writing or producing quality reports.

Consequently, grading the project report became a burden for the instructors. In order to reverse this trend, the class project assignment and writing requirements were heavily revised according to the technical writing framework. Specifically, measures were taken to focus students on the importance of specifying the role and the audience of the report, organizing the final report in clear sections, and introducing peer-review and reflection into the writing process. This was done based on the assumption that technical writing, as part of the class project, can enhance the student learning experience with NASTRAN and PATRAN.

According to the project statement at the beginning of the laboratory manual, all students in the course are assumed to be engineers in charge of investigating whether the steel bridge is safe. The ultimate purpose of their written report is to provide evidence to justify and defend their conclusions to their supervisors. In this case, their supervisors are the instructors of the class. 
Though using NASTRAN and PATRAN to analyze the steel bridge was the focus of the class project, two other analytical approaches, using field testing and using simple analytical models, were also important and necessary as they provided baseline data to justify the results of the NASTRAN and PATRAN analyses. Each of these approaches formed a task. The action items in each task were specified in the assignment statement.

As an example, the following three action items were assigned to Task 3 of NASTRAN/PATRAN analysis:

i) Use PATRAN and NASTRAN to analyze the tested steel bridge. List all assumptions involved in the finite element modeling and analysis.

ii) Report the locations where the maximal displacement and the maximal stresses occur and their values.

iii) Report the values of displacements at the locations where the dial gauges are mounted and the values of stresses at the locations where the strain gauges are mounted.

After these tasks were completed, the students were required to write and submit a progress report as a team to document the outcomes of each particular task and their learning experiences. For example, the following are the itemized report assignments introduced after Task 3 was completed.

3a) Scan any sketch papers and notes that are related to the task, include them in the report and explain their purposes.

3b) List all assumptions used in finite element solutions.

3c) Document all trial runs in this effort, including the failed trials; explain why each failed.

3d) Present the NASTRAN/PATRAN stress contour plots and

3e) Tabulate the displacement and stresses reported at the measured points and compare them with the testing results.

At the end of the project, each student team submitted a project report to their "supervisors" for approval. The final report was divided based on the assigned tasks. All final reports were required to be prepared in the form of a technical report. To ease the burden of writing, all itemized progress report assignments were arranged in such a way that they could be directly placed in the pre-designated sections in the final project report. For example, items 2c and $3 \mathrm{a}$ in the progress reports formed Section IV.1 Finite Element Modeling Procedure, while items 3b, 3c and 3d formed Section IV.2 Accuracy Analysis. Similar practices has been successfully implemented in PostLab of LabWrite ${ }^{7}$ and in Fluid Dynamics classes taught by the third author of this paper.

\section{Peer-Review and Reflection}

After the completion of each progress report, all submitted reports underwent peer-review by the entire class. Feedback collected from the peer-review process was returned back to the individual team as reference for future revisions. Furthermore, at the end of the class project, questionnaires were sent to all of the students for feedback regarding the quality of the laboratory instruction, the laboratory manual, and the class project overall. It is expected that such surveys will lead to future improvement in teaching and learning effectiveness. 


\section{Assessment}

The laboratory manual revision process was proposed and implemented in the senior elective, three credit hour class, MAE 441 in the fall 2016 semester. The revision process consisted of four major steps: 1) collecting audience responses, 2) scaffolding the class project, 3 ) project writing assignment, and 4) peer-review and reflection. In order to determine whether the proposed process was effective for improving laboratory instruction, three different types of data sets were collected. The three data sets were: 1) the standard end-of-semester student opinion survey, 2) performances in tests and the class project and 3) class reflection collected at the end of the semester. The first two data sets collected for both the fall 2015 and fall 2016 classes were summarized in Table 1 . They are used to make a comparative assessment of teaching effectiveness and learning outcomes before and after implementing revisions to the laboratory instruction and manual. Note that only the fall 2016 class used the revised laboratory manual. The third data set, class reflection, was only collected for the fall 2016 class. It was collected in order to measure the level of student engagement.

Table 1. Student Opinion Survey and Learning Outcome

\begin{tabular}{|c|c|c|c|c|c|c|c|c|}
\hline $\begin{array}{c}\text { Semester } \\
\text { Enrollment }\end{array}$ & \multicolumn{3}{|c|}{ Class Evaluation } & \multicolumn{3}{c|}{ Project Evaluation } & \multicolumn{2}{c|}{ Makeup Tests } \\
\cline { 2 - 8 } & $\begin{array}{c}\text { No. of } \\
\text { Responses }\end{array}$ & $\begin{array}{c}\text { Promoting } \\
\text { Critical } \\
\text { Thinking }\end{array}$ & $\begin{array}{c}\text { Assignments } \\
\text { Well } \\
\text { Organized }\end{array}$ & $\begin{array}{c}\text { No. of } \\
\text { Project } \\
\text { Teams }\end{array}$ & $\begin{array}{c}\text { Used } \\
\text { Beam } \\
\text { Elements }\end{array}$ & $\begin{array}{c}\text { Produced } \\
\text { Working } \\
\text { Model }\end{array}$ & $\begin{array}{c}\text { Req'd } \\
\text { for } \\
\text { Test I }\end{array}$ & $\begin{array}{c}\text { Req'd } \\
\text { for } \\
\text { Test II }\end{array}$ \\
\hline $\begin{array}{c}\text { Fall 2016 } \\
60\end{array}$ & 23 & 4.5 & 3.41 & 30 & 30 & 29 & 20 & 6 \\
\hline $\begin{array}{c}\text { Fall 2015 } \\
67\end{array}$ & 8 & 4.75 & 4.63 & 33 & None & 22 & 55 & 12 \\
\hline
\end{tabular}

\section{V.1 Teaching Effectiveness}

The first two questions of the standard student opinion report were related to the teaching effectiveness of the course. Both questions are listed below. Students were asked to rank their answers to these questions from 1 to 5 , with 1 indicating that the student strongly disagrees with the statement and 5 indicating that he or she strongly agrees with the statement.

1) The course materials, exams, projects and/or papers required me to think critically.

2) The exercises, labs and written assignments used in the courses are well constructed. Based on these two questions, the average score of 23 responses from a total of 60 students in the fall 2016 class was 4.5 and 3.41, respectively, which was surprisingly lower than the average scores reported the year before; 4.75 and 4.63, respectively. The latter scores, however, were based on only 8 responses from a total of 67 students who were enrolled in the course the year before. The major concerns of the students in the fall 2016 class were about too many assignments, lack of clearly defined deadlines for each assignment, and lack of help from teaching assistants. The results clearly indicated that the revised laboratory instruction engaged students more in the assigned class activities. However, it also indicated the need for better prelaboratory preparation and better timing for each assignment. 


\section{V.2 Learning Outcomes}

Student grades for the course were mainly based on their performance in two regular mid-term exams and the class project. The first exam was a standard in-class midterm, which tested students on NASTRAN usage to model beams and the associated joint conditions. The second midterm was an in-lab exam, which tested students on the use of PATRAN and modeling. Optional make-up tests were made available to those who failed the regular tests. Out of a total of 67 students in the fall 2015 class, 55 students requested to take the make-up test on NASTRAN and 12 requested to take the make-up test on PATRAN. However, out of 60 students in the fall 2016 class, only 20 students requested to take the make-up test on NASTRAN and only 6 requested to take the make-up test on PATRAN. This improvement was attributed to the newly introduced Adobe flash player module on the beam elements and the new examples introduced in the laboratory class on PATRAN applications.

As for the class project, in 2016, all thirty teams were able to use beams and rigid elements to model the frame and bolted joints, respectively. Only one out of thirty teams failed to produce a working model of the steel bridge at the end of the class. That was a significant improvement compared to the year before, where $30 \%$ of teams failed to produce a working model. Furthermore, quite a few students in 2016 went beyond what have been taught in class, discovering the special functionalities of PATRAN to translate and mirror parts of the model and to use 3D full span to view the orientation of the beam elements. One team even successfully conducted the vibration analysis of the steel bridge which was a pleasant surprise to the instructors. Figure 5 shows a fine 3D model of a joint connecting multiple plates and beams and Figure 6 shows the stress distribution around a bolted joint. Both figures were taken from a project report of one of the student teams in the fall 2016 class. With adequate instruction, the students in the course were able to build a detailed model of a real-world steel bridge.

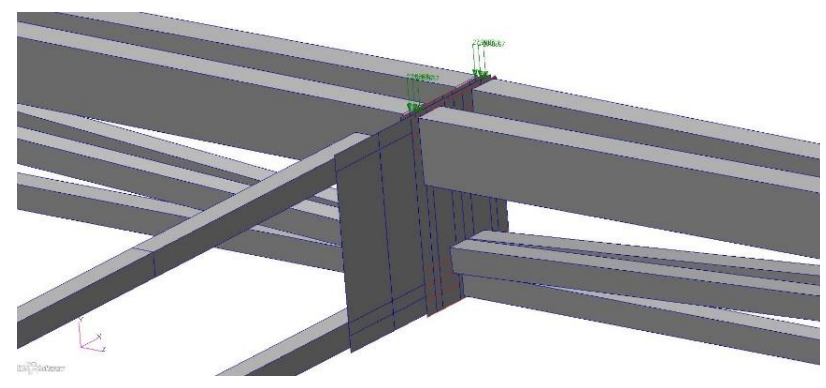

Figure 5. Details of Bridge Joint Model 


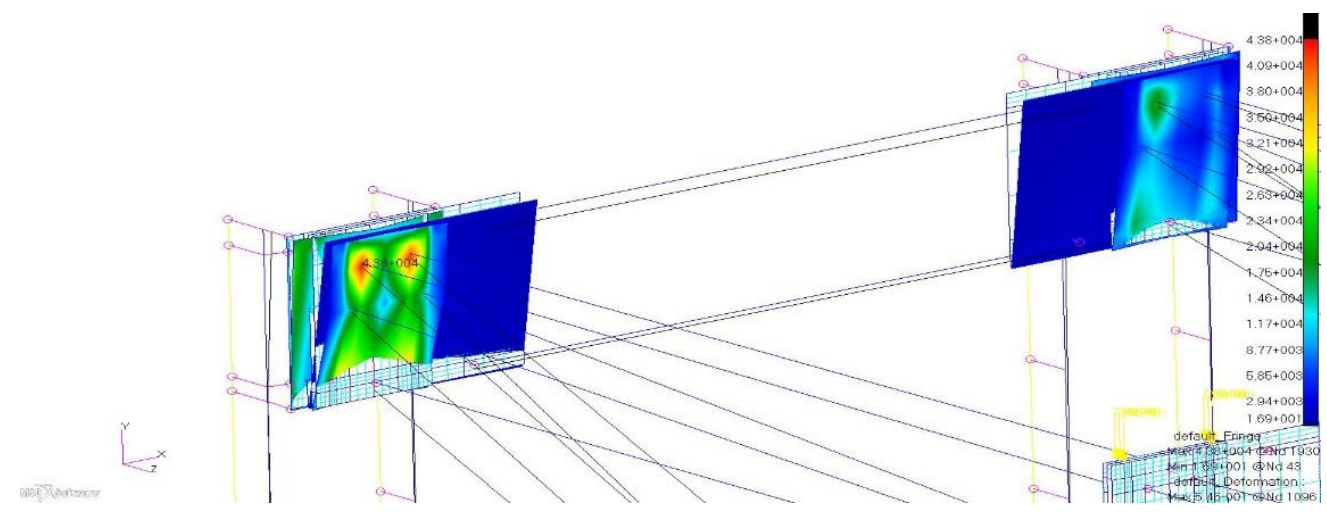

Figure 6. Maximal Stresses in the Plates

Another assessment was collected from student responses to the first three questions in the class self-reflection. Students were asked to rank their answers to these questions from 1 to 5, with 1 indicating that the student strongly disagrees with the statement and 5 indicating that he or she strongly agrees with the statement.

1) Do you agree that what you have learned from MAE 441 is important to your professional career?

2) Do you agree that the class project enriches your learning experience about using NASTRAN/PATRAN for modeling and analysis?

3) Do you agree that the laboratory manual help you in this class?

The mean score and associated standard deviation for each question collected from 39 responses out of 60 students in the fall 2016 class was $(3.92,1.14),(4.10,1.03)$ and $(4.07,0.88)$, respectively. This clearly indicated that the class project and the laboratory manual did enrich student learning experience.

\section{V.3. Improvement Suggestions}

Students were asked to answer the second set of questions in the class reflection in writing. The questions were associated with the quality of the laboratory instruction and manual. Most of the responses regarding the improvements to the laboratory manual were very articulate and helpful. They provided a comprehensive to-do list for future improvement of the laboratory manual. In this particular case, they included the following:

1) Provide more details about the available functionalities under each of the radio buttons on the first page of PATRAN GUI.

2) Correct grammar/implementation errors from pages 29 to 60 in Chapter 3.

3) Explain the orientation vector for an inclined beam in PATRAN.

4) Provide detailed step-by-step instruction on a rigid element for a simple example.

5) Provide more discussion on Grouping, Mirror/Translation and Zone in in PATRAN.

6) Explain the relation between point load assignment and remeshing

7) Provide index.

8) Provide a troubleshooting section. 
The questions given in the class reflection and some sample answers quoted from different students are listed below to demonstrate the importance of student feedback for future improvements to the class and the laboratory manual. These answers also revealed a high level of student engagement in the class.

1) Reflect on what you have learned in this project and in this class.

"I've discovered that methods of replication don't always work. I learned troubleshooting methods beyond class projects. I'm excited to have learned this much about this program and what I will be able to do with it in the future."

"...Additionally, I developed my skills in report writing through the final project task preparations."

2) Reflect on what was the most difficult part of the class project? Is there any suggestion for improvement?

"The hardest part of the project was error resolution. Once an error was integrated into the system, it is tedious to find and correct. This is amplified because Patran doesn't allow for the reversal of more than one step. It would be preferred if a step-by-step manual was developed to give the best way to approach the bridge model."

"The most difficult part of the class project was the entire model. Due to its complexity and size there were a large number of nodes. Trying to determine the exact nodes to RBE2 to one another was very difficult."

3) Comment on the quality of the laboratory manual and class instruction, and make suggestions for improvement.

"The lab manual needs to be in color, with revisions in grammar of the content and updated photos for instructional purposes. “"

"My only qualm with this class is that it was sometimes hard to find lab or homework assignments because they were placed in lecture documents. My suggestion is to utilize both the lecture and the lab section in Blackboard, so the documents can be easily found."

\section{Concluding Remarks and Discussions}

A process for laboratory manual revision was developed for a project-based laboratory class. It was then implemented in a sample project-based class, MAE 441, to investigate its impact on class instruction and student engagement. The ultimate objective of MAE 441 was to enable students to solve structural problems more complicated than those presented in the class, using the commercially-rated CAE software, NASTRAN/PATRAN. The laboratory manual for this type of class is quite different from those used in traditional, descriptive laboratory classes. The former has to serve the role of both an operations handbook, explaining hard-to-implement procedures, as well as a theoretical textbook, explaining hard-to-understand concepts. 
Furthermore, due to the constant changes in hardware, software, and class topics, this type of laboratory manuals has to be updated frequently. Teaching assistants and instructors for this type of laboratory class must also adapt to changes in relevant technology. It is thus important to keep in mind that the audience of any laboratory manual has to include both students and instructors.

The proposed laboratory manual revision process consists of four steps: 1) collecting audience responses, 2) scaffolding the class project, 3) class project writing assignment and 4) peer-reviews and reflection. It was constructed based upon the technical writing process. A critical aspect of this revision process is that it is both a continuous and sustainable process. The collection of the feedback and reflection provides specific and actionable guidelines for recursive improvement of the existing version of the laboratory manual.

As revealed in the assessment study, the proposed laboratory manual revision process greatly increased student engagement in the classroom, which in turn increased student learning effectiveness. In summary, the laboratory manual revision process proposed in this study provides one more evidence to support the core value of technical writing, which is that "writing is for learning."

\section{Acknowledgement}

The authors would express their sincere appreciation to the Director of Writing and Faculty Development from Old Dominion University, Remica Bingham-Risher, who inspired the very much rewarding work reported in this paper.

\section{References}

1. Ernst, E.W. (1983), “A New Role for the Undergraduate Engineering Laboratory," IEEE Transactions on Education, E-26(2), 49-51.

2. Feisel, L. and Peterson, G. D. (2002), "A Colloquy on Learning Objectives for Engineering Educational Laboratories", Proceedings of the 2002 American Society for Engineering Education Annual Conference \& Exposition.

3. Herrington, D. G. and Nakhleh, M. B. (2003), "What Defines Effective Chemistry Laboratory Instruction? Teaching Assistant and Student Perspectives", Journal of Chemical Education, 80(10), 1197-1205.

4. Yalvac, B., Smith, H. D., Hirsch, P. L. and Birol, G. (2006), “ Teaching Writing in a Laboratory-Based Engineering Course with a "How People Learn" Framework", Chapter 5, New Direction for Teaching and Learning, No. 108, Winter 2006, Published by Wiley Periodicals Inc., 59-73.

5. Tan, R. H. (2014), "Project-based Learning Cycles Design Framework" http://sites.psu.edu/racheltan/2014/05/13/project-based-learning-cycles/

6. Watai, L. L., Brodersen, A. J. and Brophy, S. P. (2005), "Designing Effective Electrical Engineering Laboratories using Challenge-based Instruction that Reflect Engineering Process", Proceedings of the 2005 American Society for Engineering Education Annual Conference \& Exposition.

7. Ferzli, M., Carter, M. and Weibe, E (2005)., "LabWrite: Transforming Lab Reports from Busy Work to Meaningful Learning Opportunities", Journal of College Science Teaching, 35, 31-33. 
8. Burewixa, A. and Miranowicz, N. (2006)," Effectiveness of Multimedia Laboratory Instruction", Chemistry Education Research and Practice, 7(1), 1-12.

9. Patterson, D. A. (2011), "Impact of a Multimedia Laboratory Manual: Investigating the Influence of Student Learning Styles on Laboratory Preparation and Performance over One Semester," Education of Chemical Engineers, 6, 10-30.

10. Gautam, S., Qin, Z. and Loh, K. C. (2016), "Enhancing Laboratory Experience through eLessons", Education for Chemical Engineers, 15, 19-22.

11. Piirto, J. (1996),'Teaching Writing to Engineering Students: Toward a Non-Technical Approach.”, J. Technical Writing and Communication, 20(3), 307-313.

12. Bean, J. C. (2011), Engaging Ideas: The Professor's Guide to Integrating Writing, Critical Thinking and Active Learning in the Classroom, $2^{\text {nd }}$ Edition, by John Wiley and Sons.

13. Dupen, B. (2014), "How to Improve a Textbook with Engineering Technology Students," ,Proceedings of the 2014 American Society for Engineering Education Annual Conference \& Exposition, ASEE paper no. 9101.

14. Balta, N. (2015), "A Systematic Planning for Science Laboratory Instruction: ResearchBased Evidence”, Eurasia Journal of Mathematics, Science and Technology Education, 11(5), 957-969.

15. Pandy, M. G., Petrosino, A. J., Austin, B. A. and Barr, R. E. (2004), “ Assessing Adaptive Expertise in Undergraduate Biomechanics", Journal of Engineering Education, 93(3), 211-222.

16. Girault, I., d'Ham, C., Ney, M., Sanchez, E. and Wajeman, C. (2012), "Characterizing the Experimental Procedure in Science Laboratories" A Preliminary Step Towards Students Experimental Design", International Journal of Science Education, 34 (6), 825854. 